\title{
Nanoaggregation of Polyaromatic Compounds Probed by Electrospray Ionization Mass Spectrometry
}

\author{
Lan Liu ${ }^{1}$, Johan Sjöblom ${ }^{2}$, Zhenghe $\mathrm{Xu}^{1 *}$ \\ ${ }^{1}$ Department of Chemical and Material Engineering, University of Alberta, Edmonton, Alberta, \\ Canada T6G $1 H 9$ \\ ${ }^{2}$ Ugelstad Laboratory, Norwegian University of Science and Technology, 7491 Trondheim, \\ Norway
}




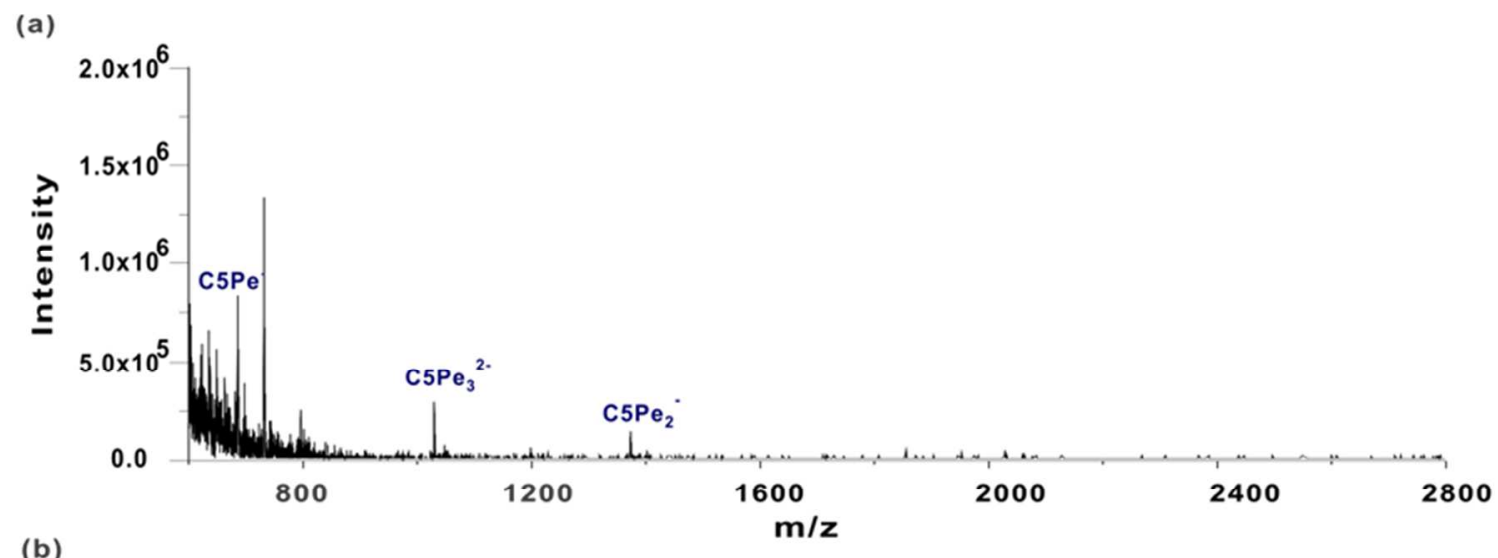

(b)

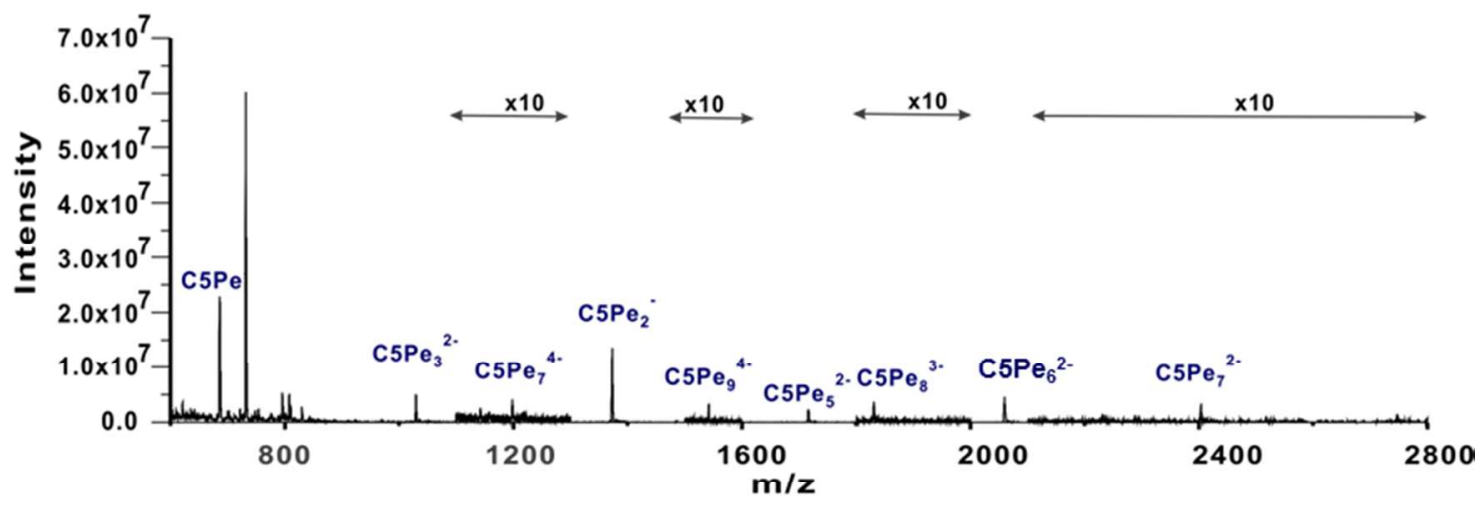

(c)

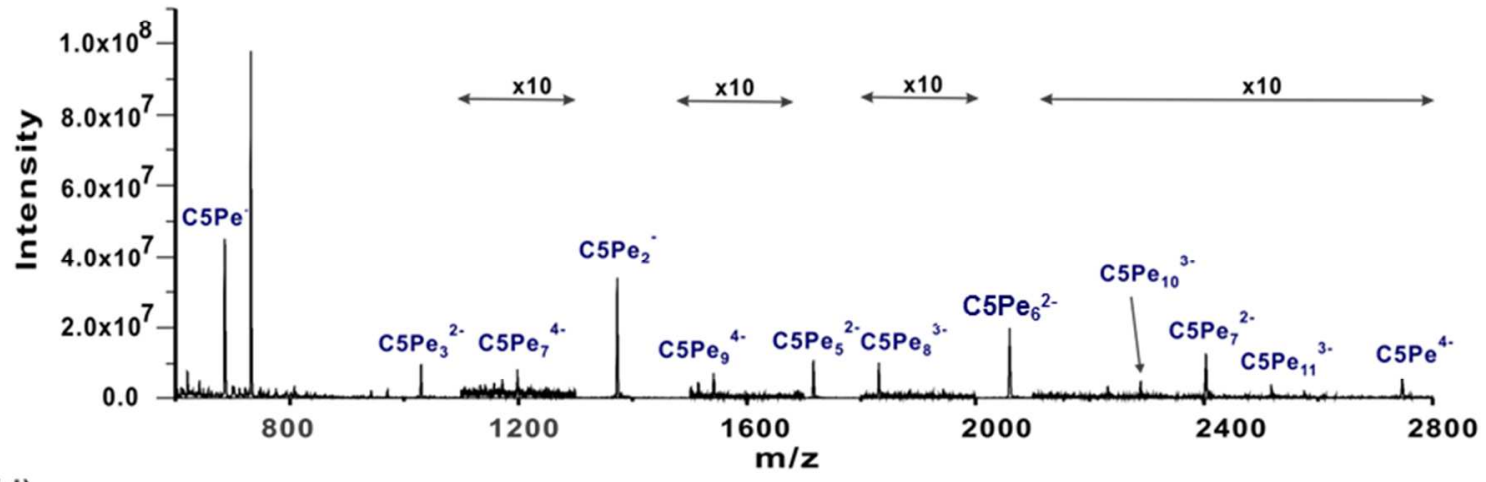

(d)

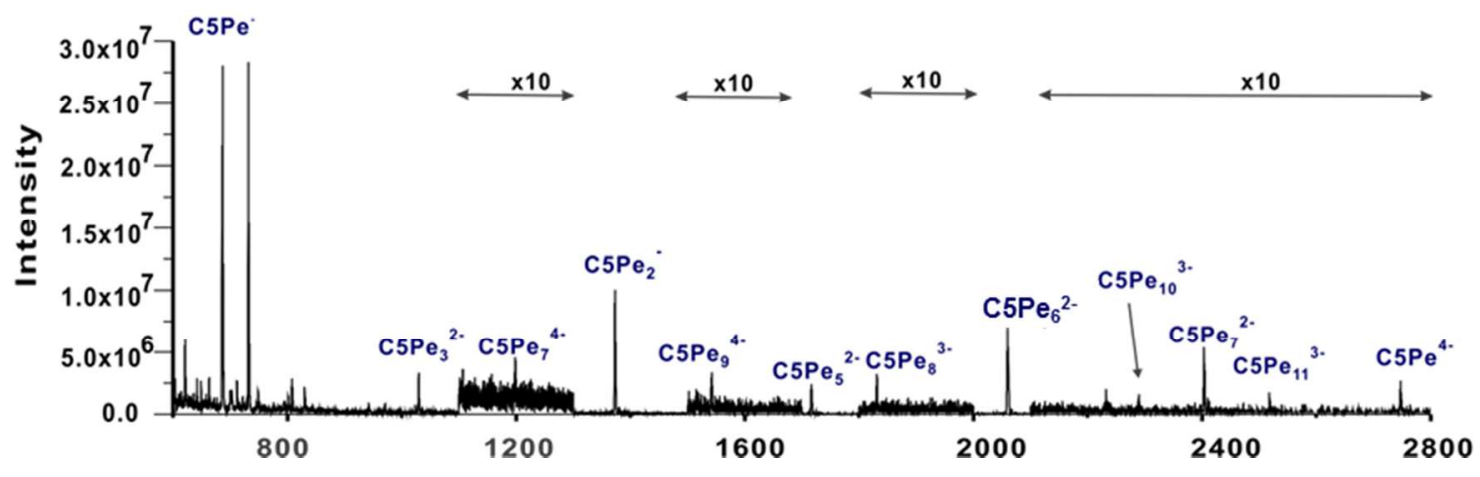


(e)

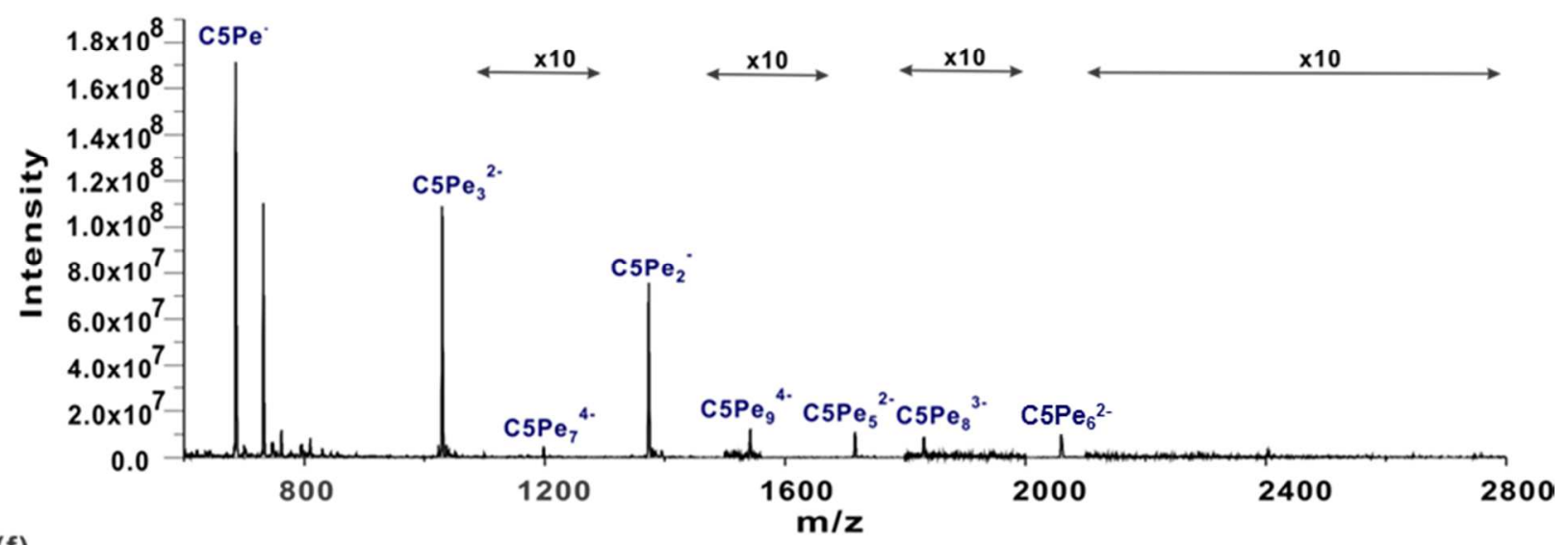

(f)

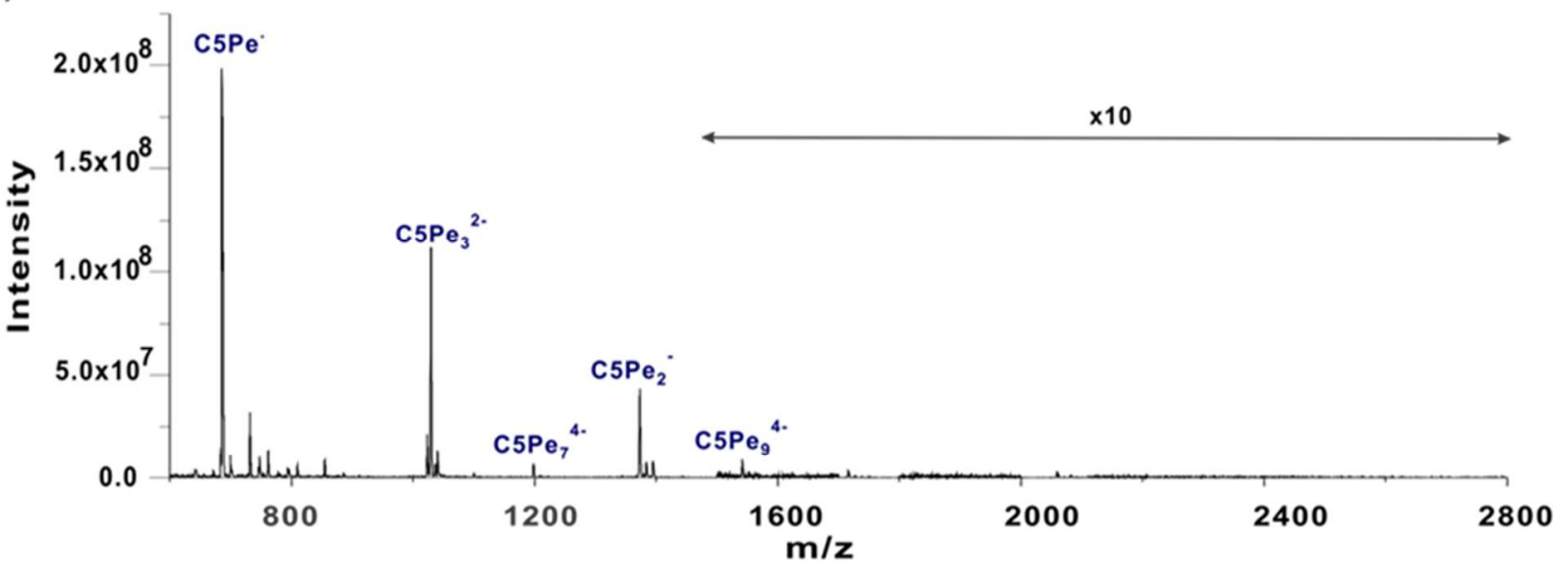

(g)

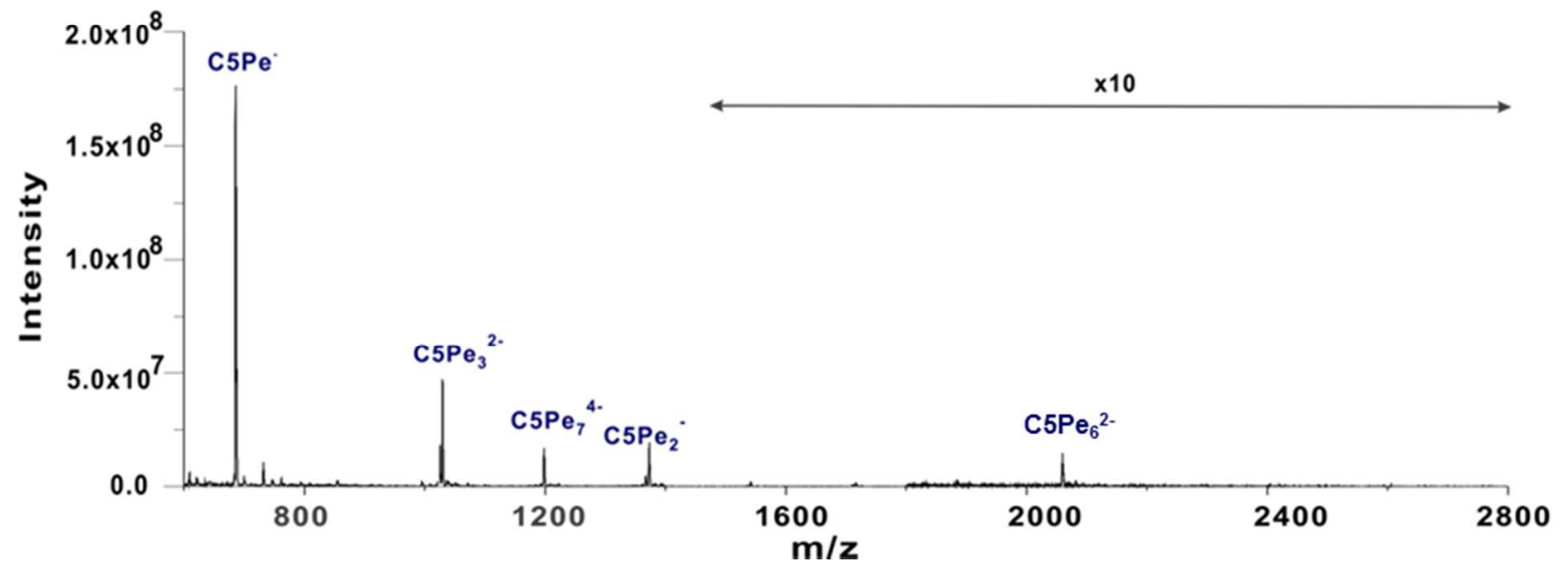

Figure S1. ESI mass spectra acquired for solutions $\left(25^{\circ} \mathrm{C}\right)$ of C5Pe $(10 \mu \mathrm{M})$ with (a) $30 \%$ methanol, $70 \%$ toluene, (b) $40 \%$ methanol, $60 \%$ toluene, (c) $50 \%$ methanol, $50 \%$ toluene, (d) $60 \%$ methanol, $40 \%$ toluene, (e) $70 \%$ methanol, $30 \%$ toluene, (f) $80 \%$ methanol, $20 \%$ toluene, and (g) $93 \%$ methanol, $7 \%$ toluene. 
(a)
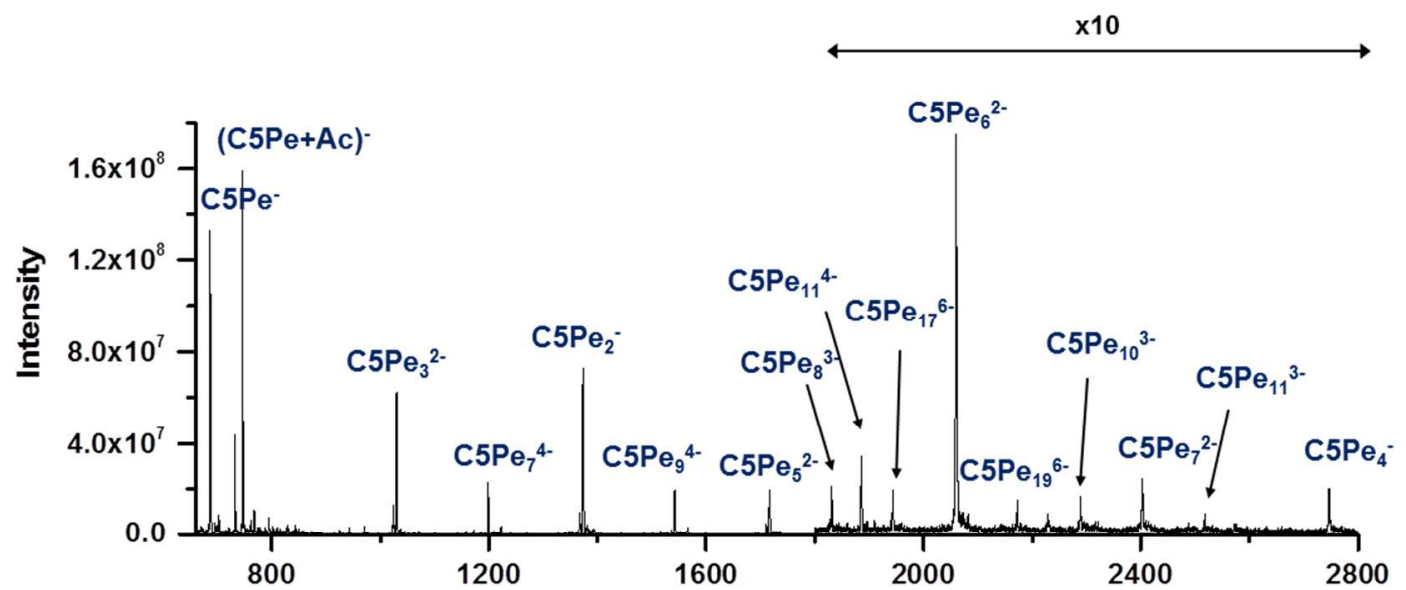

(b)

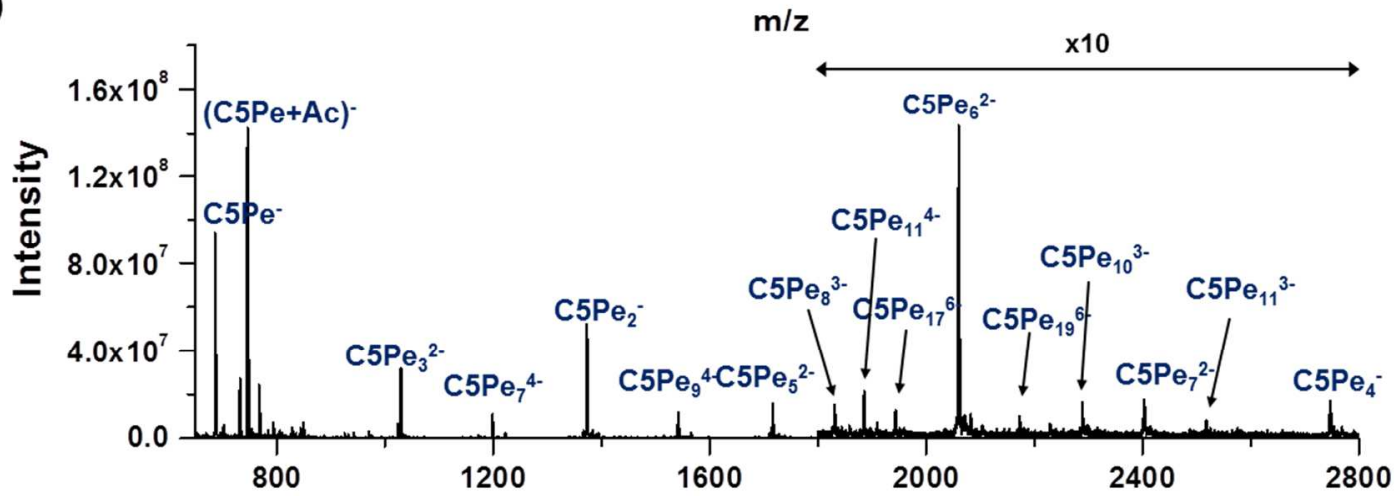

(c)

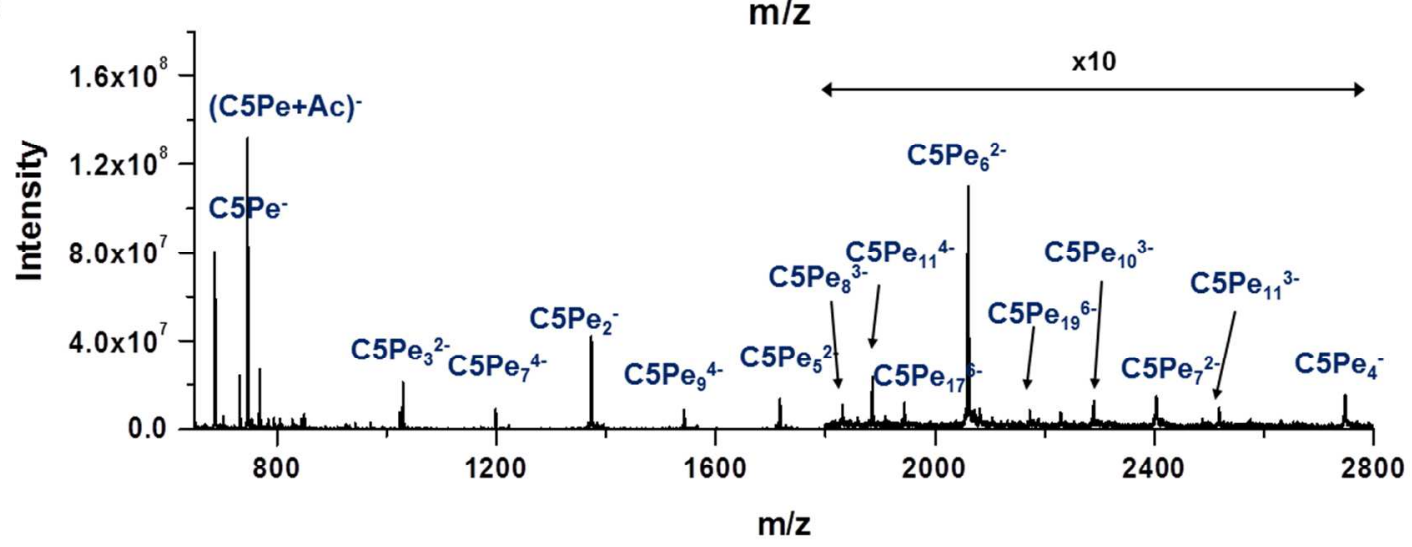

Figure S2. $\quad$ ESI mass spectra acquired for solutions $\left(25^{\circ} \mathrm{C}\right)$ of C5Pe $(10 \mu \mathrm{M})$ with (a) $4 \mathrm{mM}$ $\mathrm{NH}_{4} \mathrm{Ac}$, (b) $16 \mathrm{mM} \mathrm{NH}_{4} \mathrm{Ac}$, and (c) $28 \mathrm{mM} \mathrm{NH}_{4} \mathrm{Ac}$. Each solution contains $50 \%$ methanol and $50 \%$ toluene. 


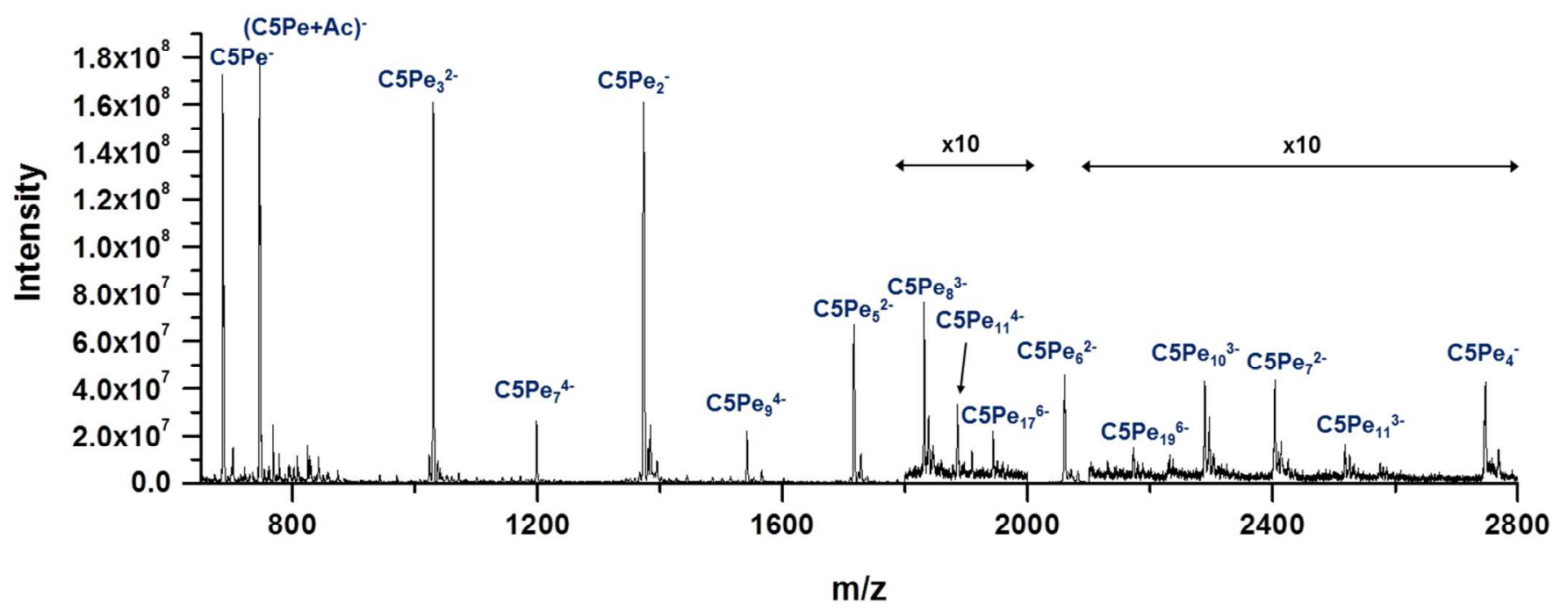

Figure S3. ESI mass spectrum acquired for solutions $\left(25^{\circ} \mathrm{C}\right)$ of $\mathrm{C} 5 \mathrm{Pe}(30 \mu \mathrm{M})$ with $4 \mathrm{mM}$ $\mathrm{NH}_{4} \mathrm{Ac}, 50 \%$ methanol and 50\% xylene. 
(a)

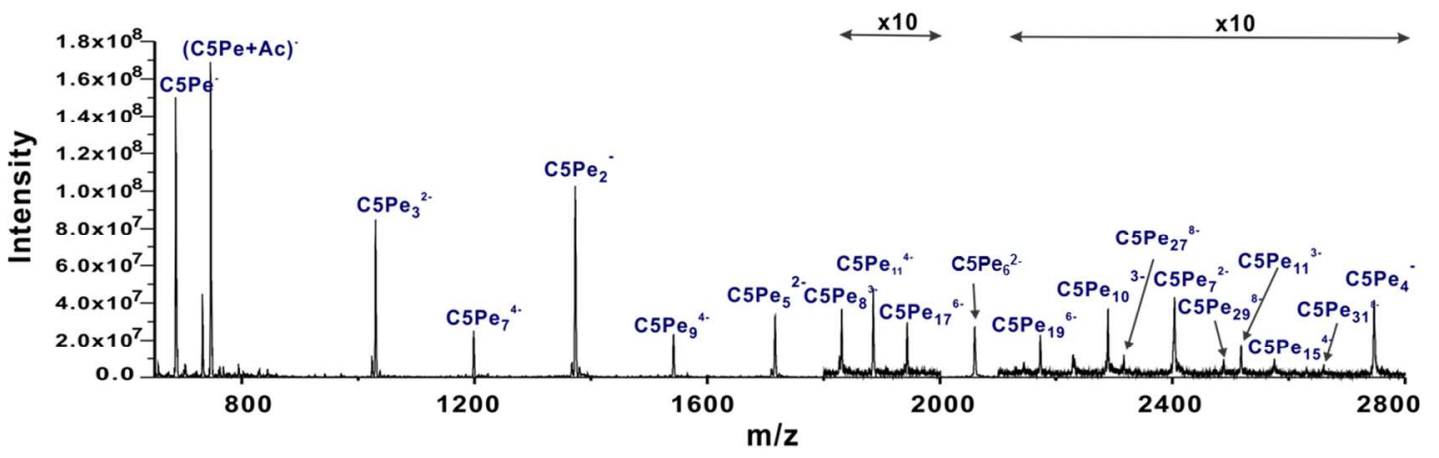

(b)

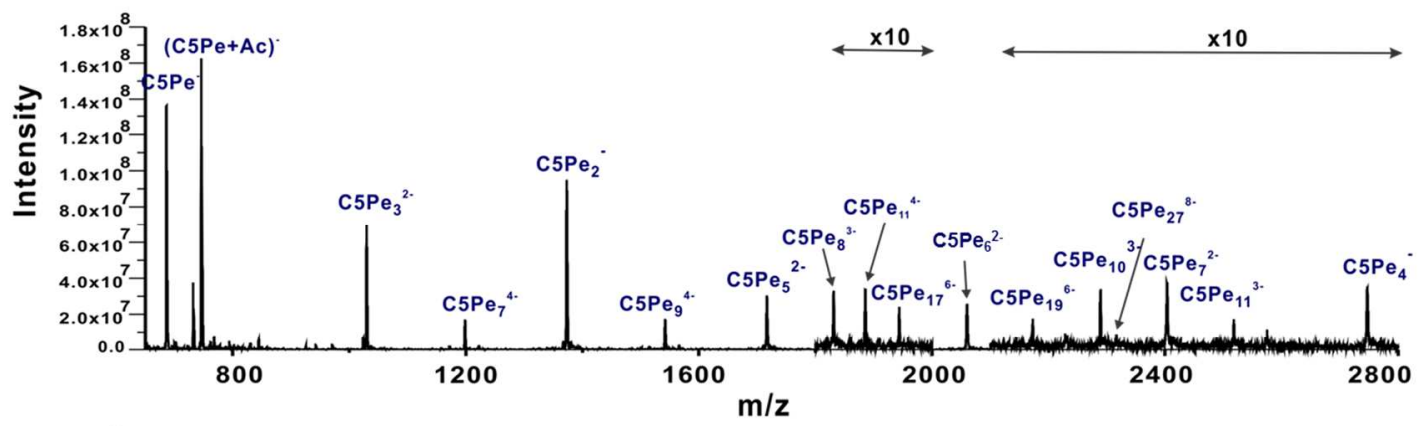

(c)

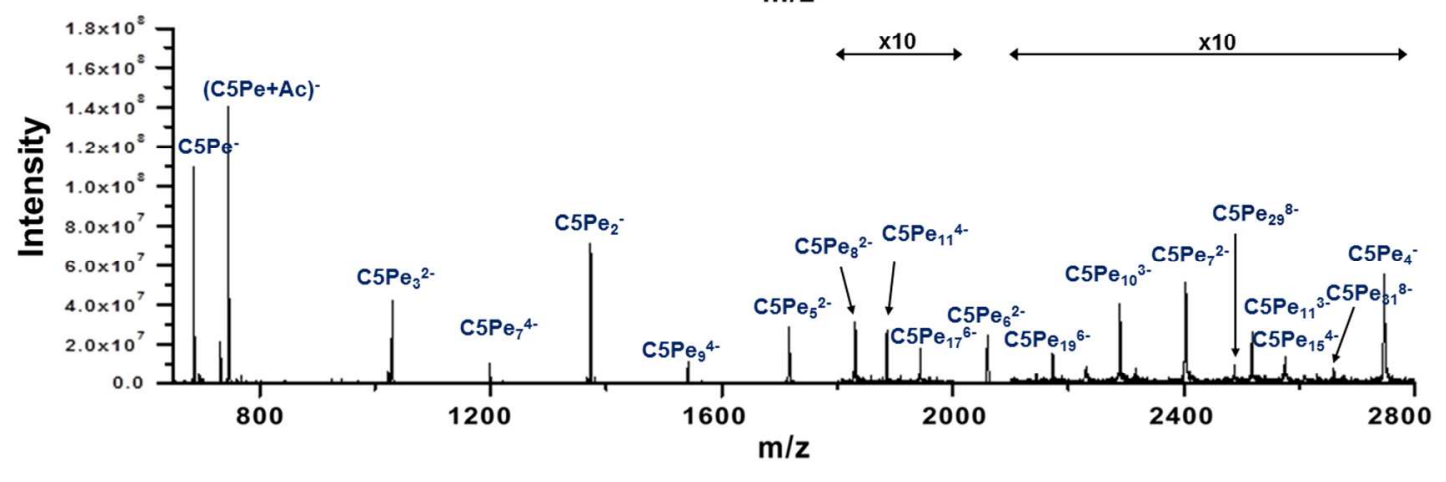

Figure S4. ESI mass spectra acquired for solutions $\left(25^{\circ} \mathrm{C}\right)$ of $\mathrm{C} 5 \mathrm{Pe}(10 \mu \mathrm{M})$ with (a) $50 \%$ methanol, 45\% toluene, 5\% heptane (b) 50\% methanol, 40\% toluene, $10 \%$ heptane, and (c) 50\% methanol, 20\% toluene, 30\% heptane. All solutions contain $4 \mathrm{mM} \mathrm{NH}_{4} \mathrm{Ac}$. 
(a)

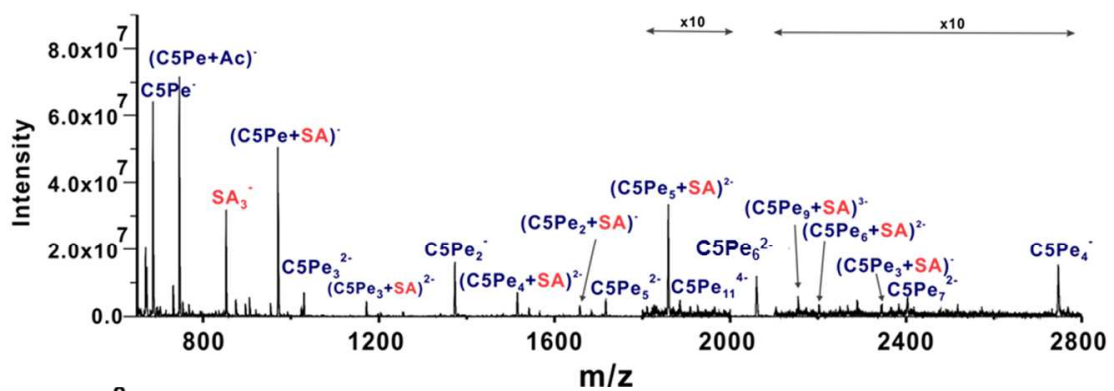

(b)

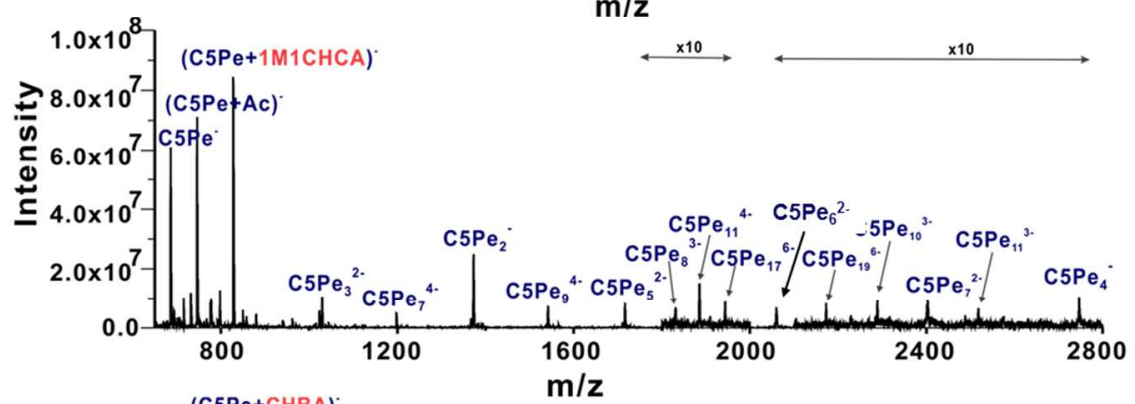

(c)

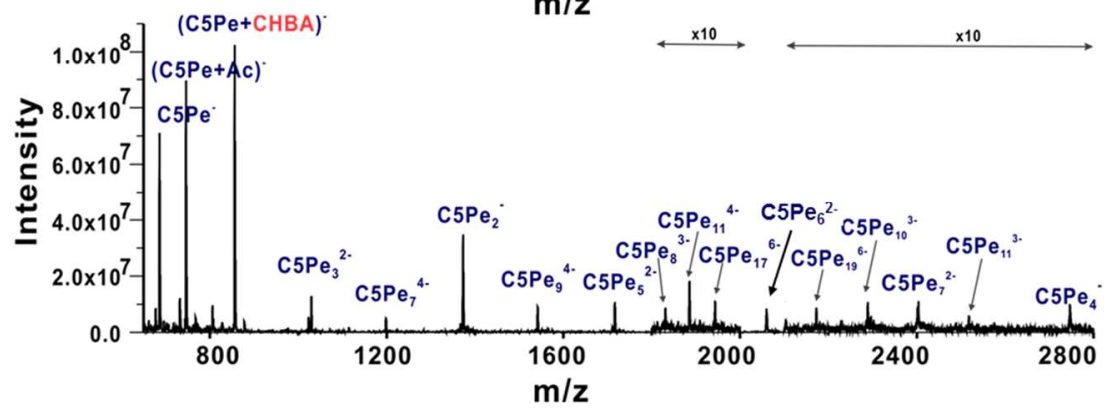

(d)

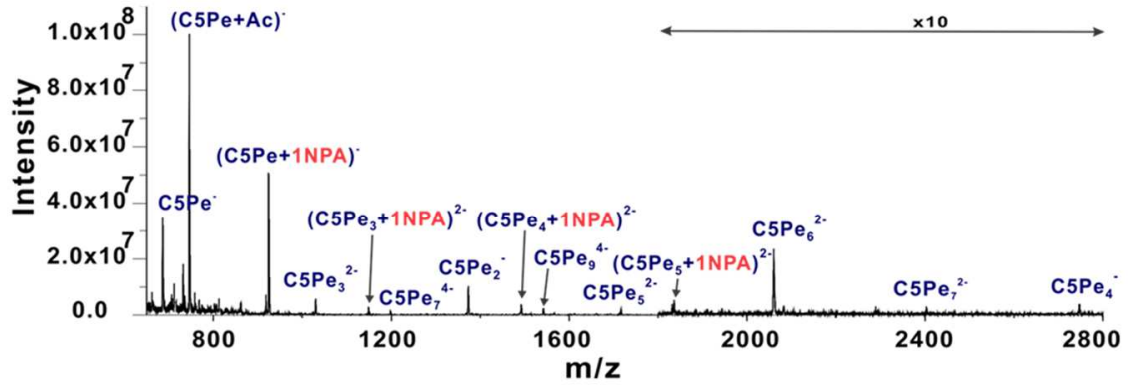

(e)

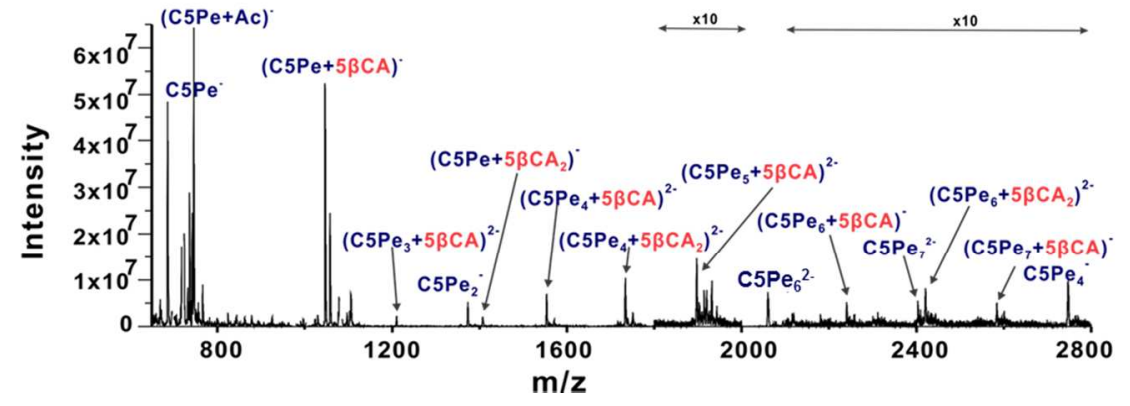

Figure S5. $\quad$ ESI mass spectra acquired for solutions $\left(25^{\circ} \mathrm{C}\right)$ of $\mathrm{C} 5 \mathrm{Pe}(10 \mu \mathrm{M})$ with (a) $32 \mu \mathrm{M}$ $\mathrm{SA}$, (b) $30 \mu \mathrm{M} 1 \mathrm{~m} 1 \mathrm{CHCA}$, (c) $35 \mu \mathrm{M}$ CHBA, (d) $30 \mu \mathrm{M} 1 \mathrm{NPA}$, and (e) $33 \mu \mathrm{M}$ $5 \beta \mathrm{CA}$. Each solution contains $4 \mathrm{mM} \mathrm{NH}_{4} \mathrm{Ac}, 50 \%$ methanol and $50 \%$ toluene. 

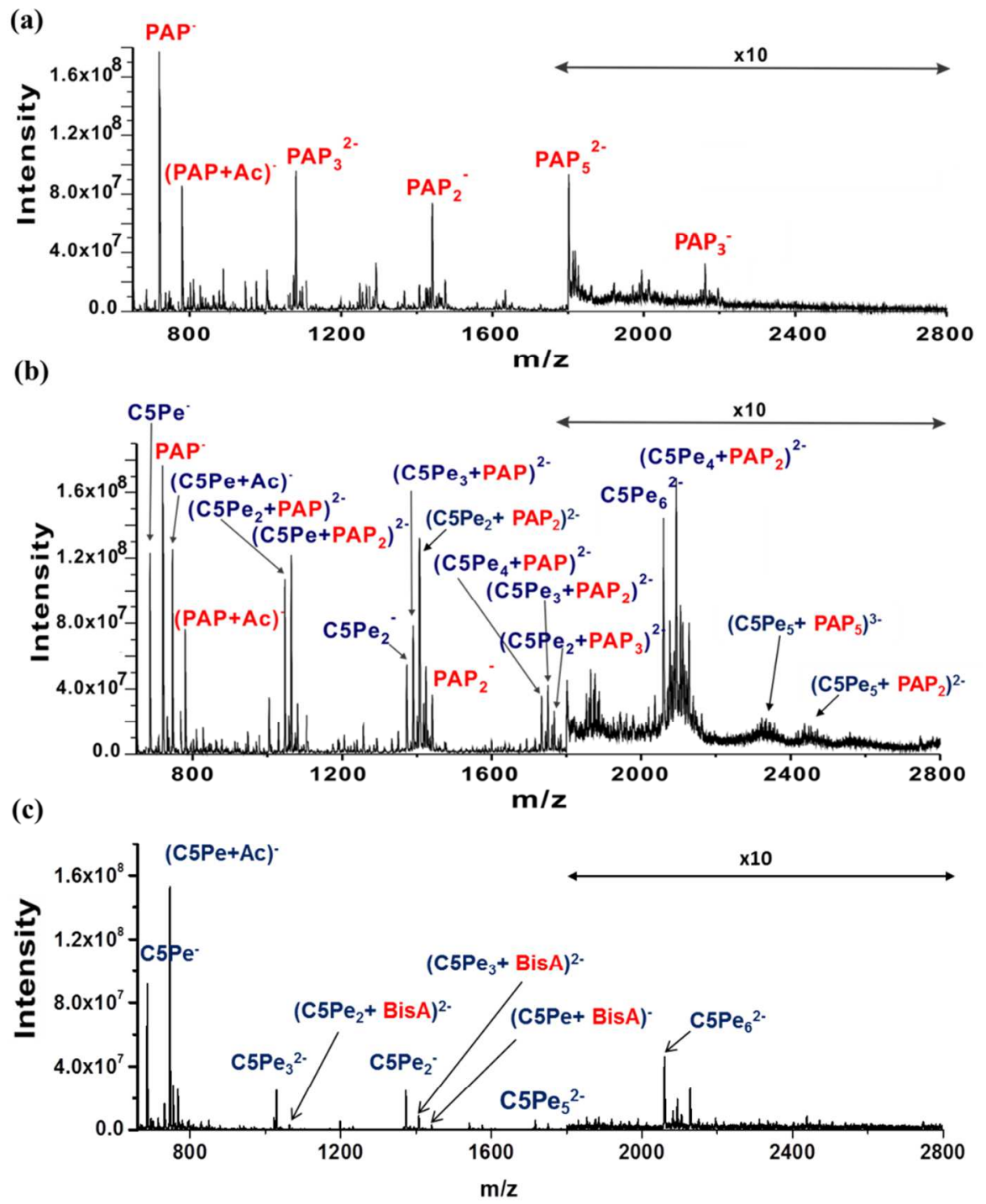

Figure S6. ESI mass spectra acquired for solutions $\left(25^{\circ} \mathrm{C}\right)$ of (a) PAP $(10 \mu \mathrm{M})$ and (b) C5Pe $(10 \mu \mathrm{M})$ and PAP $(10 \mu \mathrm{M})$. Each solution contains $4 \mathrm{mM} \mathrm{NH}_{4} \mathrm{Ac}, 50 \%$ methanol and $50 \%$ toluene. 